\title{
In Vitro evaluation of the antibacterial activity of Mucuna pruriens leaf and callus extracts
}

\author{
Melvin Samuel. S \\ School of Bio Science and Technology, VIT University, Vellore -632 014, Tamil Nadu, India. \\ Accepted 29 May, 2013
}

\begin{abstract}
The aim of this study was to evaluate the antibacterial activity of Mucuna pruriens (Velvet beans) callus culture with different hormonal combination in culture medium and leaf extracts was investigated for the maintenance of antimicrobial activity in in vitro level. The antibacterial activity was determined by the agar-well diffusion method against four different plants pathogenic bacterial species; they were Staphylococcus aureus, Bacillus subtilis, Klebsiella pneumoniae and Pseudomonas aeruginosa. Various solvents such as chloroform, methanol and ethanol were used. The leaf, node and internode segments of the plant were cultured on Murashige and Skoog (MS) medium supplemented with various growth regulators. Maximum callus formation was observed in MS medium amended with $1 \mathrm{mg} / \mathrm{L} \alpha-$ Naphthalene acetic acid (NAA). Plant cell callus culture extracts obtained from culture conditions were also bioactive and it can be a potential source of natural antioxidant and antimicrobial agent. Thus, the positive results suggest that the $M$. pruriens extracts should be further studied to determine the bioactive chemical compounds.
\end{abstract}

Key words: Mucuna pruriens, callus culture, NAA ( $\alpha-$ Naphthalene acetic acid), antimicrobial activity.

\section{INTRODUCTION}

Mucuna pruriens Bak (Fabaceae) commonly known as Kivach, Alkusi, Cowage Kaunch and Velvet bean is an economically important medicinal plant found in bushes and hedges and dry deciduous, low forests throughout the plains of India (Aguiyi et al., 1999). Seeds of this plant are rich in L-DOPA content. They have been used both as food and medicine for many other common diseases The seeds have been sold in the herbal drug stores in many parts of India. It's a wild plant and its every part of the plant has medicinal value. It's most important parts are seeds and roots. The endocarp of $M$. pruriens is nontoxic and is 2-3 times more potent than leavodopa in controlling hyperprolactinemia1 motor symptoms of Parkinson's disease animal models (Belland Jannes, 1971; Chaudhri et al., 1996; Manyam and Parikh, 2002). $M$. pruriens has also shown to exhibit neuroprotective effect by increase brain mitochondrial complex-I activity and significantly restoring dopamine and nor epinephrine levels in animal model. Phytochemical evaluation on the seeds revealed the presence of 5 -indolic compounds, especially tryptamine and 5-hydroxytryptamine 4, alkaloids like mucunine, mucunadine, prurine and prurienine. The prominent antioxidant and antimicrobial activity may be due to the presence of higher contents of phenolic, tannins and saponins (Siddhuraju et al., 2000; Sim et al., 2006; Szabo and Tebbett, 2000; Tripathi et al., 2002; Vaidya Manyam, 1978; Yamini et al., 2002). Antimicrobial substances are substances that inhibit the growth and existence of microorganisms (Ahenkora, 1999; Dongre et al., 2001; Gurumoorthi and Uma 2011). These micro organisms could be pathogenic or non pathogenic, hence, antimicrobial substances are used in the treatment of various ailments. Quite a number of antimicrobial substances exist and obtained from diverse sources such as microbial, plant, animal and chemical sources (Ani, 2008; Azontonde et al., 1998). Plants have a great potential for producing new drugs of great benefit to mankind (Cos et al., 2006; Cowan, 1999; Dako et al., 
1977). There are many approaches to the search for new biologically active principles in higher plants (Brain, 1976; Djeridane et al., 2006). The principle aim of the present work was to study the antimicrobial activity of $M$. pruriens leaf and callus extracts against plant pathogenic bacteria including $S$. aureus, B. subtilis, $P$. aeruginosa and $K$. pneumoniae. Further scope involves the isolation and identification of different constituents responsible for these activities.

\section{MATERIALS AND METHODS}

\section{Source of plant material}

The plant specimens were collected from the wild and subsequently, the identification was confirmed by Centre for Advanced Studies in Botany by Prof. N. Raaman, University of Madras, Chennai. Fresh aerial parts of Mucuna pruriens Linn. (Leguminosaceae) were collected between November to February 2009 from the Herbal Garden, Centre for Herbal Sciences, University of Madras, Guindy Campus, Chennai - 25. Leaves and node parts were collected for tissue culture work. Since the explants were collected from the field, they were subjected to sterilization process with suitable sterilants. Subsequently, the aerial parts were collected and washed thoroughly in running tap water followed by distilled water and then shade dried. The dried plants were powdered using mechanical pulverized and subjected for extraction. Sterilization: Dried glassware and media and soils for pot experiment were also sterilized in an autoclave at $20 \mathrm{lb}$ pressure for $2 \mathrm{~h}$ for 3 consecutive days. Chemicals: Analytical grade chemicals supplied by Loba, HiMedia, S.D.Fine Chemicals, E. Merck, Qualigens and Sigma Chemicals (U.S.A.) were used.

\section{Surface sterilization of explants}

From well-grown plants, the leaves and nodes were collected and washed thoroughly under running tap water for $30 \mathrm{~min}$ without damage to the tissues. In order to avoid the interaction of microbes such as bacteria and fungi in plant tissue culture, the explants were washed with sodium hypochlorite and mercuric chloride for different time duration. The explants were transferred to a beaker containing $2 \%$ sodium hypochlorite solution with rapid shaking for 20 min with changing the solution at $5 \mathrm{~min}$ interval. Then the explants were washed with distilled water. They were then treated with $0.02-$ $0.1 \%$ mercuric chloride for $1-5 \mathrm{~min}$. The surface sterilized explants were washed with sterile distilled water for 5 times (5 min each). The excess water on the explants was removed by using sterile tissue paper before culture. The explants were cut into small pieces $(0.5-1.0 \mathrm{~cm})$ barring the cut ends and transferred to semi-solid culture medium under aseptic conditions in a laminar flow chamber. For some of the nodal explants, small cuts were made.

\section{Preparation of tissue culture media}

For tissue culture, Murashige and Skoog (1962) medium was used. Six individual stocks solutions of macro, micro, minor, iron and vitamins were prepared and stored. Murashige and Skoog (1962) medium contains major elements, micro elements, minor nutrients, vitamins, Iron, Potassium lodide, Meso inositol-0.1 g/L; Sucrose $30 \mathrm{~g} / \mathrm{L} ;$ Agar $-8 \mathrm{~g} / \mathrm{L} ; \mathrm{pH}-5.6$ to 5.8. Iron stock was stored in a black bottle to prevent photolysis of chemicals. All the stock solutions were stored in refrigerator. Meso-inositol, cytokinin and auxin stock solutions were freshly prepared. For preparation of medium, all the
6 stock solutions were mixed thoroughly with required amounts of sterile distilled water. Sucrose 3\% (30 g/L), 0.1\% meso-inositol (100 $\mathrm{mg}$ ) and required amount of plant growth hormones were added to the medium and buffered by $1 \mathrm{~N} \mathrm{HCl}$ or $1 \mathrm{~N} \mathrm{NaOH}$ to adjust the medium $\mathrm{pH}$ to 5.6 before autoclaving. The medium was solidified by adding $0.8 \%$ agar $(800 \mathrm{mg} / \mathrm{L})$. Sterile distilled water was used to make the final volume. The medium was poured into culture vials and autoclaved. After inoculated with explants, all culture vials were kept under $16 / 8 \mathrm{~h}$ (light/dark) photoperiod at $25 \pm 2^{\circ} \mathrm{C}$.

\section{Preparation of hormone stock solutions}

Auxins 2, 4-dichlorophenoxyacetic acid (2, 4-D), Indole-3-acetic acid (IAA), Indole-3-butyric acid (IBA) and a-napthalene acetic acid (NAA) and cytokinins BAP (6-benzylaminopurine), KIN - Kinetin (6furfurylaminoourine) and Gibberellic acid (GA3) were prepared and stored at $4^{\circ} \mathrm{C}$. 2,4-D, (M.W. 221.0), $100 \mathrm{mg}$ was dissolved in $1.0 \mathrm{~mL}$ of $1 \mathrm{~N} \mathrm{KOH}$ and heated. Water was added to make a final volume of $100 \mathrm{~mL}(1.0 \mathrm{mg} / \mathrm{mL})$. IAA, (M.W. 175.2), $100 \mathrm{mg}$ was dissolved in $1.0 \mathrm{~mL} 1 \mathrm{~N} \mathrm{KOH}$. Warm water was added to make final volume of $100 \mathrm{~mL}(1.0 \mathrm{mg} / \mathrm{mL})$. IBA, (M.W. 203.2), $100 \mathrm{mg}$ was dissolved in $1.0 \mathrm{~mL} 1 \mathrm{~N} \mathrm{NaOH}$. Warm water was added to make a final volume of $100 \mathrm{~mL}(1.0 \mathrm{mg} / \mathrm{mL}$ ). NAA, (M.W. 186.2), $100 \mathrm{mg}$ was dissolved in $1.0 \mathrm{~mL} 1 \mathrm{~N} \mathrm{NaOH}$. Water was added to make final volume of 100 $\mathrm{mL}(1.0 \mathrm{mg} / \mathrm{mL}$ ). BAP (Benzyl adenine), (M.W. 225.2), $100 \mathrm{mg}$ was dissolved in $1.0 \mathrm{~mL}$ of $1 \mathrm{~N} \mathrm{HCl}$ and heated slowly. Water was added to make final volume of $100 \mathrm{~mL}(1.0 \mathrm{mg} / \mathrm{mL})$. KIN (Kinetin), (M.W 215.2), $100 \mathrm{mg}$ was dissolved in $1.5 \mathrm{~mL} 1 \mathrm{~N} \mathrm{KOH}$. Water was added to make a final volume of $100 \mathrm{~mL}(1.0 \mathrm{mg} / \mathrm{mL})$.GA3 (Gibberellic acid), (M.W. 330.0), $100 \mathrm{mg}$ dissolved in $1.0 \mathrm{ml} 1 \mathrm{~N} \mathrm{KOH}$. Water was added to make a final volume of $100 \mathrm{~mL}(1.0 \mathrm{mg} / \mathrm{mL})$.

\section{Culture incubation conditions}

The cultures were incubated in culture chamber at $25 \pm 2^{\circ} \mathrm{C}$ for light condition, the culture vials were placed on the rack at a distance 25 $\mathrm{cm}$ from the light source. A $16 / 8 \mathrm{~h}$ (light/dark) photoperiod of cool white light was provided from 2000 lux fluorescent tubes. Dark incubation was kept in the dark chamber or by wrapping culture vials and plants with aluminum foil.

\section{Tissue culture of plants}

\section{Callus induction}

For callus induction, healthy and disease free young green leaves, shoot tips, axillary buds and internodes were collected from oneyear old plants and they were used as explants. Surface sterilized explants, $0.5-1.0 \mathrm{~cm}$ segments were placed on the semi-solid MS basal medium supplemented with 2,4-D (1 mg/L), IAA (1 mg/L), NAA (1 mg/L), BAP (1 mg/L) and KIN (0.5-4.0 mg/L) individually and in combinations and incubated under dark at $25 \pm 2^{\circ} \mathrm{C}$ for $5 \mathrm{~d}$, then transferred into light condition.

\section{Phytochemical analysis of Leaf and callus of M. pruriens}

The plant powder was soaked directly in methanol in the ratio of 1:4 $(\mathrm{w} / \mathrm{v})$ and left for $24 \mathrm{~h}$. The extract was filtered using Whatmann filter paper No.1. To the residue, methanol was added again and the process continued till the color of the filtrate was pale. All the filtrates were pooled together and concentrated to $2 \%$ of its original volume using Buchi-R-153 rotary evaporator under reduced pressure. The brown calli were dried and powdered. The methanol extract was prepared from the brown callus. The extract was subjected to various preliminary photochemical analyses to check 
the presence of phenolic compounds. The extract was also used for antimicrobial activity.

\section{Qualitative phytochemical screening}

The different qualitative chemical tests were performed for establishing the profile of given extract for its chemical composition. The following tests were performed on the extracts to detect various phytoconstituents present in them. Detection of alkaloids: Solvent free extract $(50 \mathrm{mg})$ was stirred with a few milliliter of dilute hydrochloric acid and filtered. The filtrate was tested carefully with various alkaloidal reagents as follows: Mayer's test: To a few milliliter of filtrate, a drop or two of Mayer's reagent was added by the sides of the test tube. A white creamy precipitate indicated the test as positive. Detection of carbohydrates and glycosides: The extract $(100 \mathrm{mg})$ was dissolved in $5 \mathrm{~mL}$ of water and filtered. The filtrate was subjected to the following tests. Fehling's, Benedict's, Borntrager's, Foam test, Millon's, Biuret, Ninhydrin, Ferric chloride.

\section{Thin layer chromatography}

Silica gel for TLC (SRL) was used for Thin Layer Chromatography. The crude methanolic leaf, stem and callus were spotted at $2 \mathrm{~cm}$ from the edge of the sheet. The chromatogram was developed in a mixture of suitable solvent system and dried at room temperature. The spots were visualized with UV light at $356 \mathrm{~nm}$. Alternatively, the developed TLC plates were placed in iodine chamber. The $R_{f}$ values of the colored spots were recorded.

\section{Antibacterial activity of M. pruriens}

The organisms tested against were two Gram positive bacteria (Bacillus subtilis, Staphylococcus aureus) and 2 Gram negative bacteria (Pseudomonas aeruginosa and Klebsiella pneumoniae). All the organisms were obtained as the clinical specimens from the Department of Microbiology, Institute of Basic Medical Sciences (IBMS), University of Madras, Taramani, Chennai, India. Fresh cultures were prepared by inoculating the organisms in Mueller Hinton $(\mathrm{MH})$ broth and incubating at $37^{\circ} \mathrm{C}$ for $24 \mathrm{~h}$. Each organism was suspended in sterile broths and diluted to contain $10^{6}$ colony forming units (CFU) per $\mathrm{mL}$ by matching the turbidity of the tube with standard 0.5 McFarland solutions.

\section{Evaluation of antibacterial activity by agar well diffusion method}

Mueller Hinton Agar (MHA) medium was used for preparation of plates. Medium (3.8 g) was dissolved in $100 \mathrm{~mL}$ of distilled water and sterilized and $25 \mathrm{~mL}$ of the medium was poured to the depth of $4 \mathrm{~mm}$ in sterile Petri plates of $90 \mathrm{~mm}$ dia. The agar was allowed to solidify at ambient temperature. In each plate, using a sterile borer of $6 \mathrm{~mm}$ diameter, 4 wells were cut in the agar plate. A sterile cotton swab was immersed into the standardized bacterial suspension and pressed against the wall of the tube to remove excess fluid. MHA plates were inoculated by streaking with that swab. Streaking was done successively in 3 different directions to obtain even spread of inoculum. The concentrated leaf and stem extracts of the wild and tissue cultured callus were weighed and dissolved in dimethyl sulfoxide (DMSO) to prepare extract solution of $1 \mathrm{mg}$ in $1 \mathrm{~mL}$ of DMSO (1000 $\mu \mathrm{g} / \mathrm{L}$ concentration). To each well, concentration ranging from 50 to $300 \mu \mathrm{L}$ of this extract solution was dispensed using a sterile micropipette. The inoculated plates were incubated within $15 \mathrm{~min}$ of inoculation at $37^{\circ} \mathrm{C}$ for $24 \mathrm{~h}$. Then the plates were examined for any zone of growth inhibition. Inhibition zones were recorded as the diameter of growth free zones including the diameter of the well in $\mathrm{mm}$ at the end of incubation period.
The percentage of inhibition was calculated by the formula: \% of inhibition $=$ I (Diameter of the inhibition zone) $\times 100 / 90$ (Diameter of the Petri-plate in $\mathrm{mm}$ )

\section{RESULTS}

\section{Surface sterilization}

The surface sterilization of leaf explants of Mucuna pruriens Linn was carried with $0.5 \%$ sodium hypochlorite solution for $15 \mathrm{~min}$. It was then surface sterilized with mercuric chloride. The concentration of mercuric chloride and the duration of the treatment were standardized. $94 \%$ contamination free explants were obtained when the concentration of mercuric chloride was $0.05 \%$ treated for time duration of $2 \mathrm{~min}$. Treatment of the leaf explants with $0.1 \%$ concentration of mercuric chloride for time duration of $2 \mathrm{~min}$ helped to obtain $86 \%$ contamination-free explants. When treatment was extended to $3 \mathrm{~min}$, some of the explants got killed and only $58 \%$ surviving explants were obtained. The surface sterilization of nodal and internode explants of $M$. pruriens was carried with $0.5 \%$ sodium hypochlorite solution for $15 \mathrm{~min}$. It was then surface sterilized with mercuric chloride. The concentration of mercuric chloride and the duration of the treatment were standardized. $100 \%$ contamination free explants were obtained when the concentration of mercuric chloride was $0.1 \%$ for time duration of $4 \mathrm{~min}$. The treatment with $0.1 \%$ mercuric chloride for $3 \mathrm{~min}$ and $0.05 \%$ mercuric chloride for 5 min helped to obtain $93 \%$ and $95 \%$ contamination-free explants, respectively.

\section{Callus formation of leaf explants}

Murashige and Skoog (MS) medium supplemented with different growth hormones helped in obtaining callus from leaf explants of $M$. pruriens. Much response was not obtained from leaf explants. The MS medium supplemented with NAA (1 mg/mL) showed friable callus in $62 \%$ of the leaf explants. NAA $(0.5 \mathrm{mg})$ induced $45 \%$ callus formation. Callus induction was observed after 6 days of culture. MS medium without activated charcoal produced green callus initially, which turned brown in 3-5 days. The chemicals produced by the brown callus changed the medium to yellow color. When activated charcoal $(1 \mathrm{~g} / \mathrm{L})$ was added to MS medium, green callus was obtained. Friable callus was also obtained when the culture bottles were stored in complete darkness. Hormones other than NAA did not show any significant induction of callus compared to control (Table 1 and Figure 1).

\section{Callus formation of nodal explants}

The callus formation in nodal explants of $M$. pruriens was obtained on MS medium supplemented with different growth hormones. Among the hormones used, NAA (1 $\mathrm{mg} / \mathrm{L}$ ) showed maximum callus formation of about $89 \%$, followed by NAA $(0.5 \mathrm{mg} / \mathrm{L})$ which showed callus 
Table 1. Effect of different plant growth hormones on callus formation from leaf and node explants of Mucuna pruriens.

\begin{tabular}{lll}
\hline Concentration of hormone & Leaf explant (\%) & Nodal explants (\%) \\
\hline IAA $(0.5 \mathrm{mg})$ & -- & 45 \\
IAA $(1 \mathrm{mg})$ & -- & 54 \\
IBA $0.5 \mathrm{mg})$ & -- & 56 \\
IBA $(1 \mathrm{mg})$ & -- & 60 \\
IBA $(1.5 \mathrm{mg})$ & -- & 68 \\
NAA $(0.5 \mathrm{mg})$ & 45 & 72 \\
NAA $(1 \mathrm{mg})$ & 62 & 89 \\
IAA $(0.3 \mathrm{mg})+$ KIN $(0.2 \mathrm{mg})$ & -- & 65 \\
IAA $(0.5 \mathrm{mg})+$ KIN $(0.6 \mathrm{mg})$ & -- & 66 \\
IAA $(0.3 \mathrm{mg})+$ BAP $(0.2 \mathrm{mg})$ & -- & 60 \\
IAA $(0.5 \mathrm{mg})+\operatorname{BAP}(0.6 \mathrm{mg})$ & -- & 59 \\
\hline
\end{tabular}
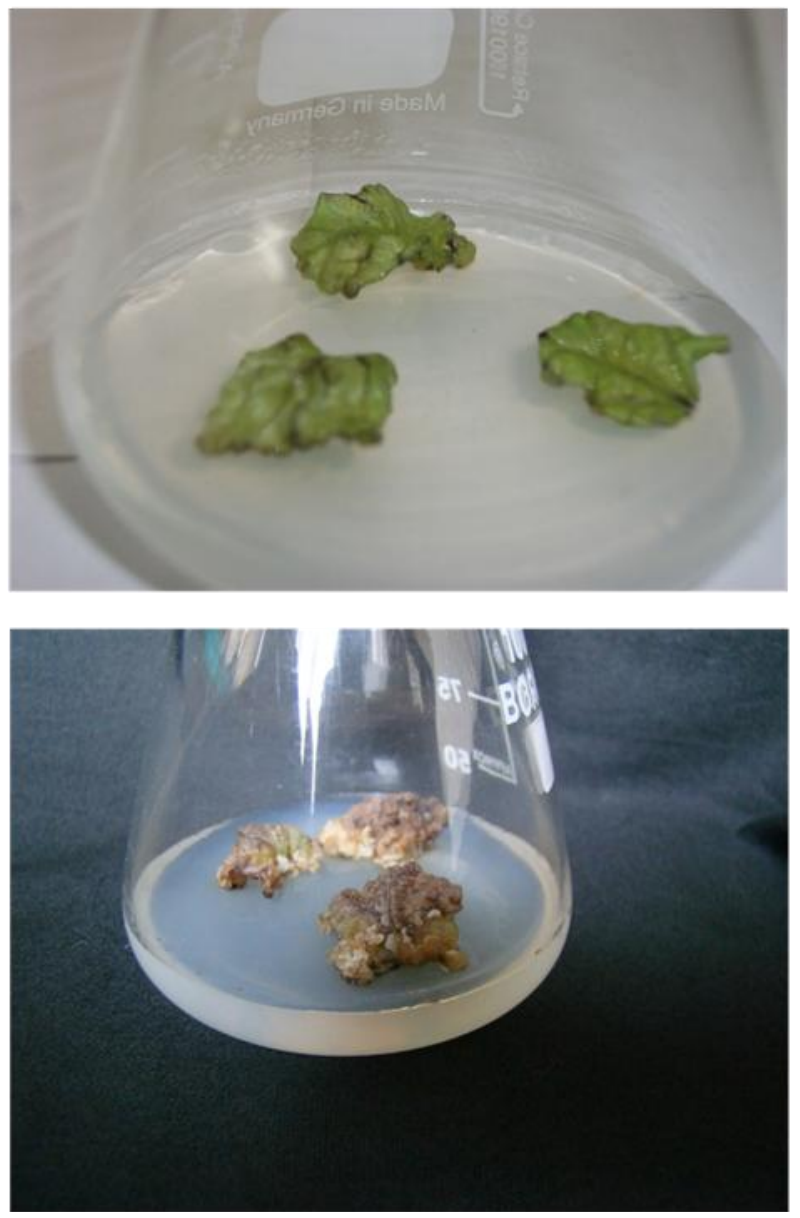

Figure 1. Callus formation of leaf explants. A, Callus induction from leaf of $M$. Pruriens at 5 th day; $b$, callus development from leaf of M. Pruriens at 28th day.

formation of $72 \%$. IBA $(1.5 \mathrm{mg} / \mathrm{L})$ showed significant callus production of $68 \%$. IAA in combination with cytokinins (KIN and BAP) also showed significant callus induction (Table 1 and Figure 2).
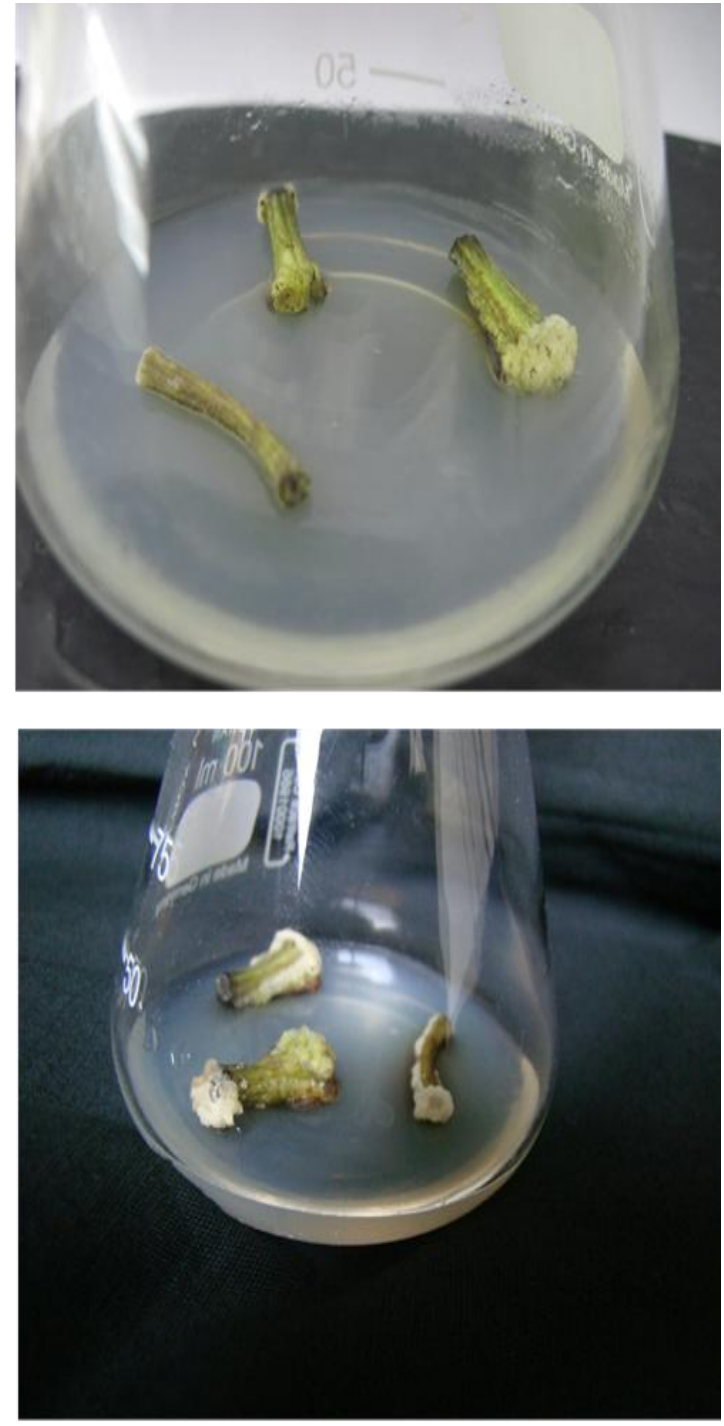

Figure 2. Callus formation of nodal explants. A, Callus induction from internode of $\mathrm{M}$. Pruriens at 8th day; $b$, callus development from internode of $M$. Pruriens at 20th day. 
Table 2. Qualitative analysis of the phytochemicals of the medicinal plant Mucuna pruriens Linn.

\begin{tabular}{lcc}
\hline Phytochemical Test & Leaf & Callus \\
\hline Alkaloids & & \\
Mayer's Test & ++ & ++ \\
Carbohydrates & & \\
Fehling's Test & ++ & ++ \\
Benedict's Test & +++ & +++ \\
Molisch's Test & +++ & +++ \\
Glycosides & & \\
Borntrager's Test & +++ & +++ \\
Saponins & & \\
Foam Test & + & - \\
Proteins and Amino Acids & & \\
Biuret Test & & \\
Ninhydrin Test & ++ & ++ \\
Phenolics & ++ & ++ \\
Ferric Chloride Test & & \\
Alkaline reagent Test & ++ & ++ \\
Phytosterol & ++ & ++ \\
Libermann-Burchard's Test & & \\
\hline
\end{tabular}

Table 3. TLC profile of methanolic leaf extract of Mucuna pruriens (Retention factor).

\begin{tabular}{lccccccc}
\hline & \multicolumn{7}{c}{ Compounds observed with leaf extract } \\
\cline { 2 - 9 } Parameter & \multicolumn{7}{c}{$\mathbf{R}_{\mathbf{f}}(\mathbf{S F}=\mathbf{7 . 0})$} \\
\cline { 2 - 9 } & $\mathbf{1}$ & $\mathbf{2}$ & $\mathbf{3}$ & $\mathbf{4}$ & $\mathbf{5}$ & $\mathbf{6}$ & $\mathbf{7}$ \\
\hline Visible & 0.12 & 0.24 & 0.35 & 0.39 & 0.52 & - & - \\
UV & 0.12 & 0.24 & 0.35 & 0.39 & 0.52 & - & - \\
lodine & 0.12 & 0.24 & 0.35 & 0.39 & 0.52 & 0.63 & 0.77 \\
\hline
\end{tabular}

${ }^{*} R_{f}$ - Retention factor, SF- Solvent front.

\section{Preliminary phytochemical analysis}

From the preliminary phytochemical analysis, leaf and stem extracts of $M$. pruriens showed the presence of contain alkaloids, carbohydrates, glycosides, saponins, phytosterols, protein and amino acids. Ferric Chloride test and alkaline reagent tests confirmed high amount of phenolic content present in this plant. The phenolic content of callus extract was less compared to leaf and stem extracts. The callus extract did not respond to the foam test, hence the no saponins present in the callus extract (Table 2).The extract can be used to isolate compounds in future.

\section{Thin Layer Chromatography (TLC)}

TLC was run on silica gel coated glass plates. After separation, the presence of compounds was observed for visible spots, under UV light and in iodine chamber. The
TLC profile of methanolic leaf extract showed five visible spots with different $R_{f}$ values $(0.19,0.24,0.35,0.39$ and 0.52). A better separation was obtained in Hexane: Ethyl acetate: Methanol (13:5:2) solvent system. The same spots were observed under UV light. Two additional spots were observed then the TLC was placed in iodine vapour with $R_{f}$ values 0.63 and 0.77 . The spots are different phytochemicals of the leaf, which can be separated through a column chromatography (Table 5 and Figure 6). It was interesting to observe the TLC profile of methanolic callus extract separated with the same solvent system (Hexane: Ethyl acetate: Methanol $(13: 5: 2))$. Six visible spots were observed with $R_{f}$ values $0.12,0.23,0.56,0.81,0.91$ and 0.97 . All the above six spots were also seen in UV light and iodine vapour. The leaf, and callus extracts showed the presence of few common phytochemicals $\left(R_{\mathrm{f}}\right.$ values between: $0.10-0.12$, $0.23-0.24,0.56,0.49-0.54$ and 0.76-0.77) (Tables 3 and 
Table 4. TLC profile of methanolic callus extract of $M$. pruriens (Retention factor).

\begin{tabular}{lcccccc}
\hline & \multicolumn{6}{c}{${ }^{*} \mathbf{R}_{\mathbf{f}}(\mathbf{S F}=\mathbf{7 . 5})$} \\
\cline { 2 - 7 } Parameter & \multicolumn{7}{c}{ Compounds observed with callus extract } \\
\cline { 2 - 7 } & $\mathbf{1}$ & $\mathbf{2}$ & $\mathbf{3}$ & $\mathbf{4}$ & $\mathbf{5}$ & $\mathbf{6}$ \\
\hline Visible & 0.12 & 0.23 & 0.56 & 0.81 & 0.91 & 0.97 \\
UV & 0.18 & 0.23 & 0.56 & - & 0.91 & 0.97 \\
lodine & 0.18 & 0.23 & 0.56 & 0.81 & 0.91 & 0.97 \\
\hline
\end{tabular}

${ }^{*} R_{f}-$ Retention factor, SF- Solvent front.

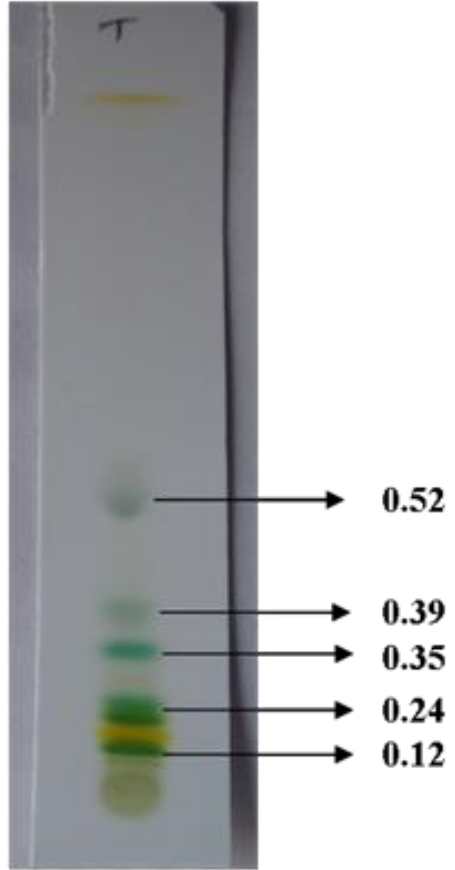

a

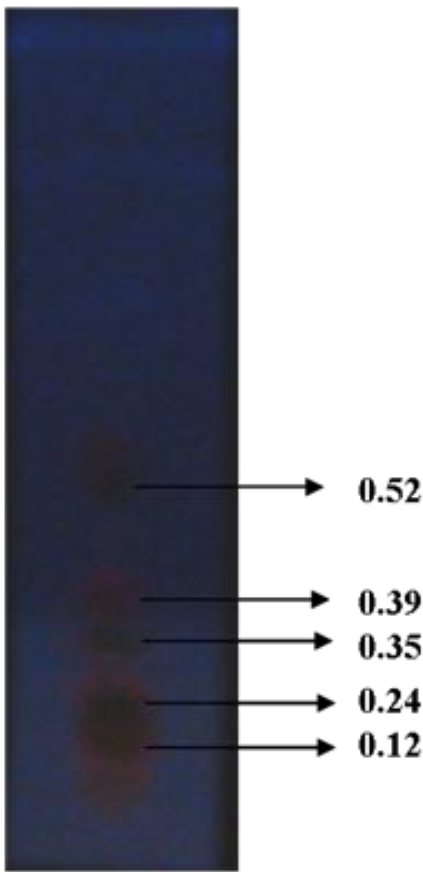

b

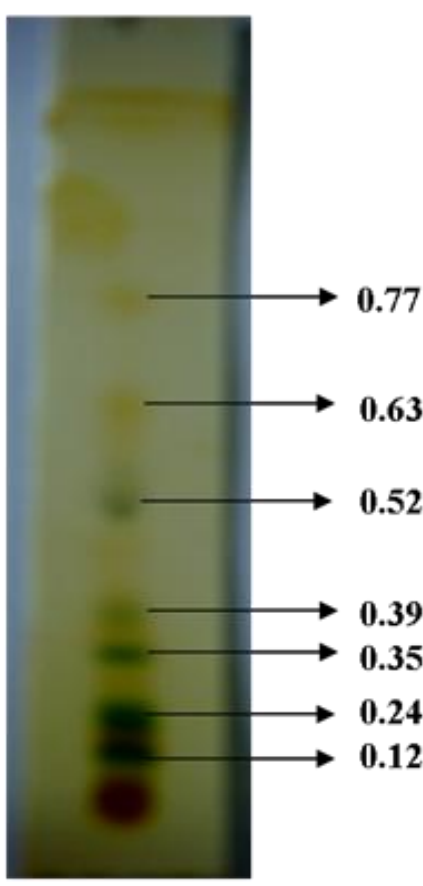

c

Solvent system $=$ Hexane $:$ Ethyl acetate: Methanol $\quad$ Solvent front $=7.1 \mathrm{~cm}$ $(13: 5: 2)$

Values given above indicate the Rf of different compounds

Figure 3. Thin layer chromatography of methanolic leaf extract of M. Pruriens. A, TLC of leaf extract under visible light; b, TLC of leaf extract under UV light (356nm); c, TLC of leaf extract exposed to iodine vapour.

4) and (Figures 3 and 4).

\section{Determination of Phenolic content}

The total phenolic content of methanolic extract of leaf, stem and callus was determined according to the method of Singleton and Rossi (1965). The leaf extract showed maximum phenolic content $(110.5 \mathrm{mg} / \mathrm{g})$ compared to callus $(92.4 \mathrm{mg} / \mathrm{g})($ Table 5$)$.

\section{In vitro antioxidant assay}

The in vitro antioxidant potential of methanolic extract of leaf, and callus was carried out using DPPH assay. The extracts were compared with the standard antioxidants Quercetin and Ascorbic acid. All the extracts (leaf, stem and callus) showed significant antioxidant activity at higher concentrations ( 250 and $500 \mu \mathrm{g} / \mathrm{mL}$ ). The $\mathrm{IC}_{50}$ value value of the stem methanolic extract was around 25 $\mu \mathrm{g} / \mathrm{mL}$, whereas the $I_{50}$ values of the stem and callus 


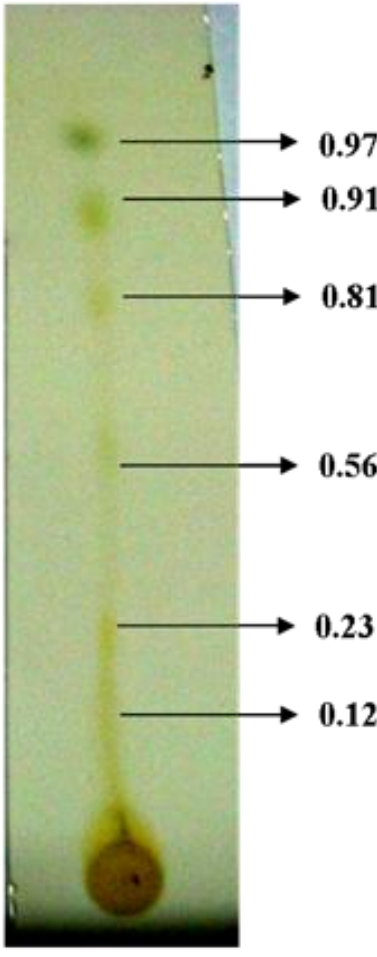

a

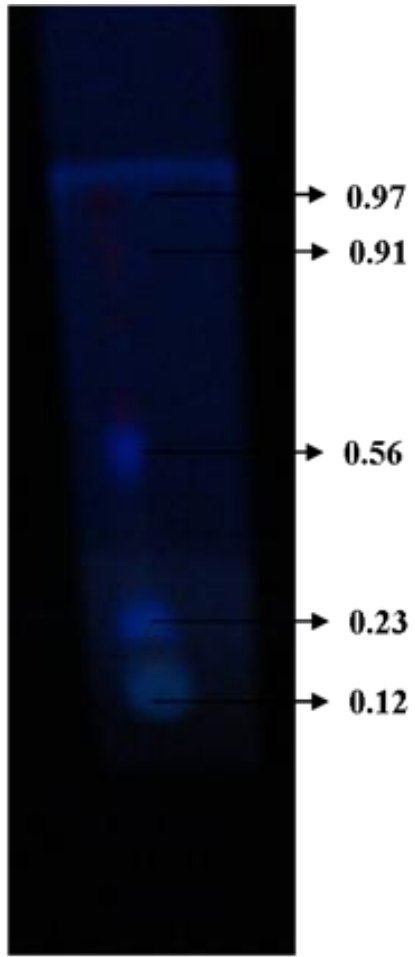

b

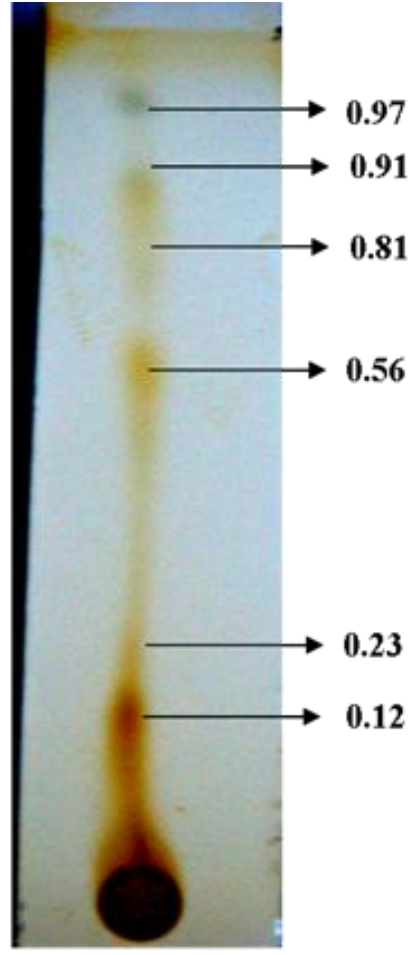

c

\section{Solvent system $=$ Hexane $:$ Ethyl acetate: Methanol $\quad$ Solvent front $=8.2 \mathrm{~cm}$}

$(13: 5: 2)$

\section{Values given above indicate the Rf of different compounds}

Figure 4. Thin layer chromatography of methanolic callus extract of M. Pruriens. A, TLC of callus extract under visible light; b, TLC of callus extract under UV light (356 nm); c, TLC of callus extract exposed to iodine vapour.

Table 5. Estimation of Phenolic content in methanolic leaf extracts of $M$. pruriens

\begin{tabular}{lc}
\hline Plant part used & Phenolic content $(\mathbf{m g} / \mathbf{g})$ \\
\hline Leaf & 110.5 \\
Callus & 92.4 \\
\hline
\end{tabular}

were also around $60 \mu \mathrm{g} / \mathrm{mL}$. The lower concentrations showed negligible activity. The callus extract showed an $\mathrm{IC}_{50}$ value near to that of stem. The enhanced production of these secondary metabolites that contain antioxidant activity can be achieved by cell suspension culture in future (Table 6).

\section{Antimicrobial activity}

Standard antibacterial agent Streptomycin was used at a concentration of $20 \mu \mathrm{g}$ for the comparative studies. The methanolic extract of leaf and callus of $M$. pruriens showed significant inhibitory activity against four ATCC human pathogenic bacterial species namely $S$. aureus, $B$. subtilis, $P$. aeruginosa, K. pneumoniae. The antibacterial activity of the plant crude extracts was found to be dose dependent and showed good activity at $100 \mu \mathrm{L}$ concentration. Leaf and stem extract did not show any inhibition zone against Pseudomonas aeruginosa. Whereas callus extract showed inhibition zone against $P$ seudomonas aeruginosa. Callus extract and leaf extracts showed activity ranging from $13 \%$ to $18 \%$ at $100 \mu \mathrm{g}$ concentration against all the bacterial species tested (Tables 7 and 8) and (Figures 5 and 6).

\section{DISCUSSION}

The present work focused on in vitro propagation of leaf, node and internode explants for callus formation. A comparison of antioxidant and antibacterial activity of in vitro callus and wild leaf were carried out. Maximum contamination free leaf explants (94\%) were obtained when the concentration of mercuric chloride was $0.05 \%$ 

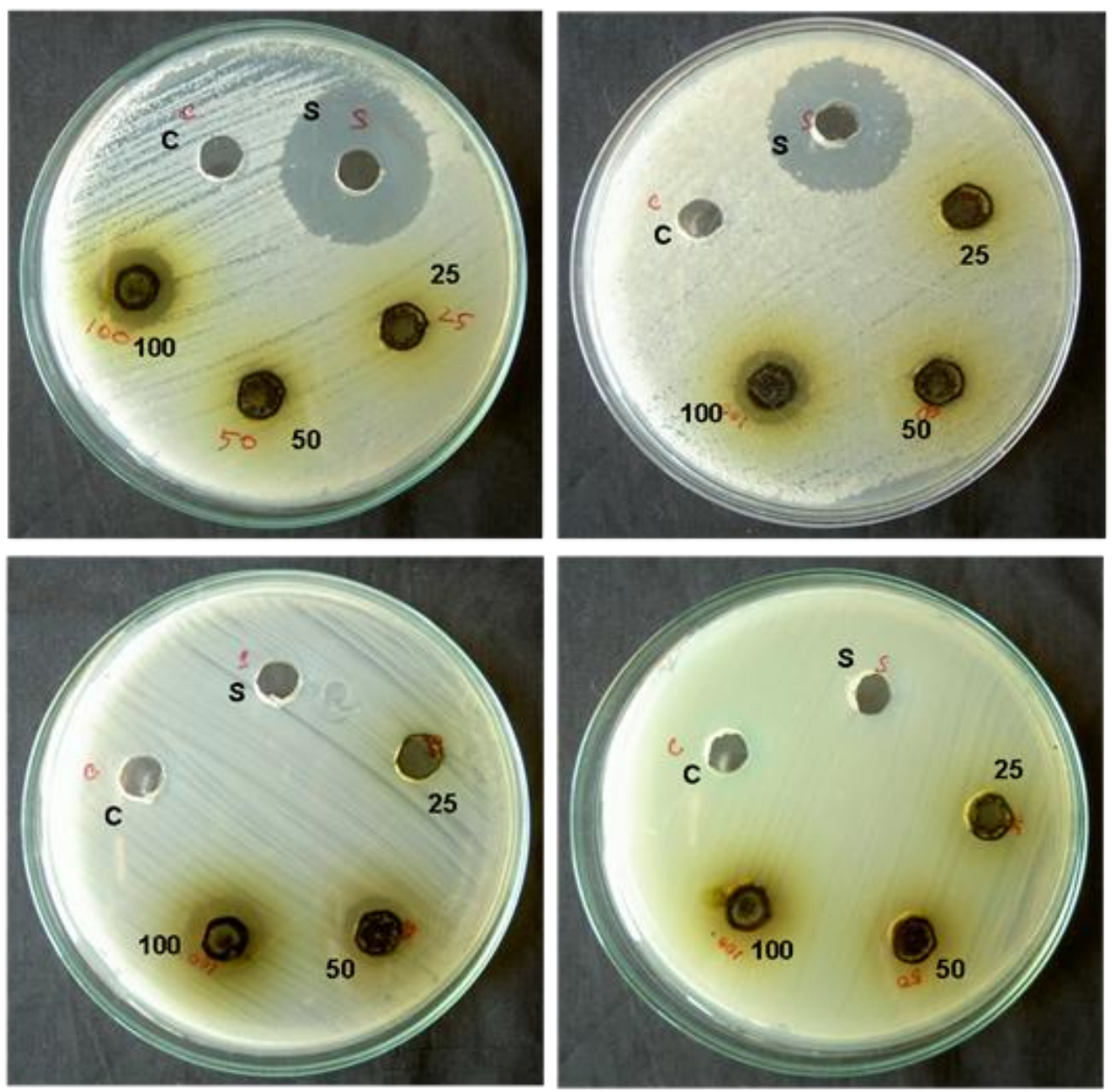

\section{$25-25 \mu \mathrm{L}$ of leaf extract \\ $50-50 \mu \mathrm{L}$ of leaf extract \\ $100-100 \mu \mathrm{L}$ of leaf extract \\ C - Control \\ S - Standard antibiotic (Streptomycin)}

Figure 5. Antibacterial activity of methanolic leaf extract of M. Pruriens. A, S. Aureus; b, B. Subtilis; c, K. pneumoniae; d, P. aeruginosa.

Table 6. In vitro antioxidant activity (DPPH assay) of methanolic leaf, and callus extracts of M. pruriens.

\begin{tabular}{lcccccccc}
\hline \multirow{2}{*}{ Conc. $(\mu \mathrm{g} / \mathrm{mL})$} & \multicolumn{2}{c}{ Methanol extract (leaf) } & \multicolumn{2}{c}{ Methanol extract (Callus) } & \multicolumn{2}{c}{ Quercetin } & \multicolumn{2}{c}{ Ascorbic acid } \\
\cline { 2 - 8 } & OD & \% inhibition & OD & \% inhibition & OD & \% inhibition & OD & \% inhibition \\
\hline 8 & 1.276 & 20.15 & 1.35 & 15.52 & 0.794 & 50.31 & 0.86 & 46.18 \\
16 & 1.15 & 28.04 & 1.24 & 22.40 & 0.689 & 56.88 & 0.76 & 52.44 \\
32 & 0.62 & 61.20 & 0.93 & 41.80 & 0.35 & 78.10 & 0.41 & 74.34 \\
63 & 0.57 & 64.33 & 0.76 & 52.44 & 0.24 & 84.98 & 0.27 & 83.10 \\
125 & 0.43 & 73.09 & 0.52 & 67.46 & 0.22 & 86.23 & 0.21 & 86.86 \\
250 & 0.41 & 74.34 & 0.37 & 76.85 & 0.181 & 88.67 & 0.183 & 88.55 \\
500 & 0.32 & 79.97 & 0.31 & 80.60 & 0.134 & 91.61 & 0.164 & 89.74 \\
\hline
\end{tabular}

Control value: 1.598 ; OD: Optical density at $517 \mathrm{~nm}$. 

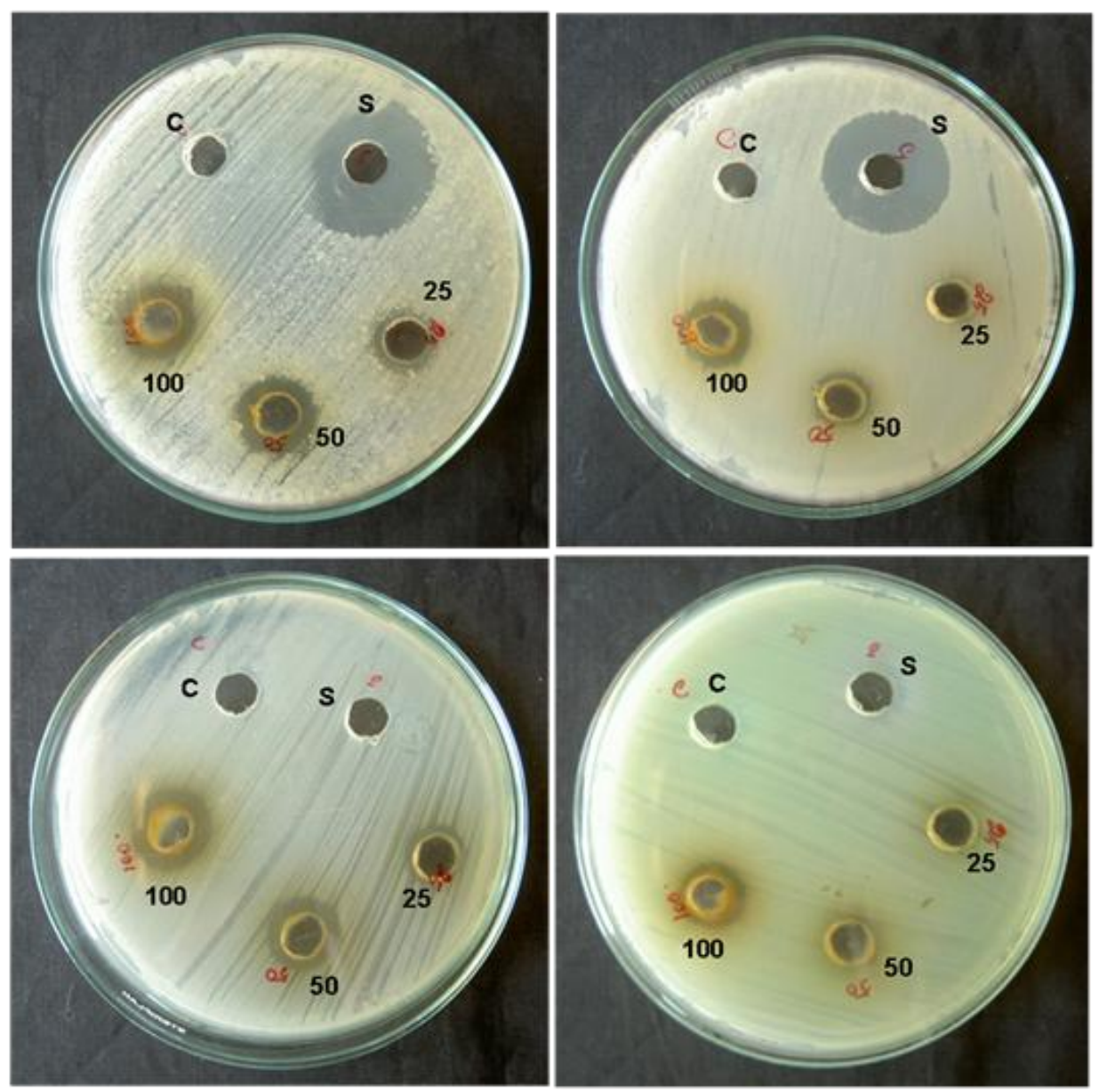

$$
\begin{aligned}
& 25-25 \mu \mathrm{L} \text { of callus extract } \\
& 50-50 \mu \mathrm{L} \text { of callus extract } \\
& 100-100 \mu \mathrm{L} \text { of callus extract } \\
& \mathrm{C}-\text { Control } \\
& \mathrm{S}-\text { Standard antibiotic (Streptomycin) }
\end{aligned}
$$

Figure 6. Antibacterial activity of methanolic callus extract of M. Pruriens. A, S. Aureus; b, B. Subtilis; c, K. pneumoniae; d, P. aeruginosa.

treated for time duration of 2 min whereas $100 \%$ contamination free node and internode explants were obtained when the concentration of mercuric chloride was $0.1 \%$ for time duration of 4 minutes. In vitro clonal propagation of $M$. pruriens and its evaluation of genetic stability through random amplified polymorphic DNA (RAPD) markers were carried out by Sathyanarayana et al. (2008). According to their study the auxiliary bud from 14-day-old seedlings were cultured on MS medium and maximum percentage of shoot elongation was observed in BAP amended medium. An efficient micro-propagation system for $M$. pruriens using cotyledonary node explants was developed (Pant and Joshi, 1970; Guerranti et al., 2002; Rai et al., 2009; Scotter, 2011). A range of cytokinins was investigated for multiple shoot regeneration with cotyledonary node explants from 7-day old aseptic seedlings. Of all the cytokinins, BAP and KIN was the most effective and $5.0 \mu \mathrm{M}$ was found to be optimum for inducing maximum shoots (Eilittä and Carsky, 2003; Guerranti et al., 2001; Hairiah et al., 1993).

In the present study, the callus induction from leaf, node and internode explants were standardized in MS medium amended with different concentrations of auxins and cytokinins. Maximum callus formation was observed in MS medium amended with $1 \mathrm{mg} / \mathrm{L}$ NAA in all explants types. Leaf explants showed moderate callus formation compared to shoot and internode explants. The antioxidant activity of $M$. pruriens on in vivo models was repor- 

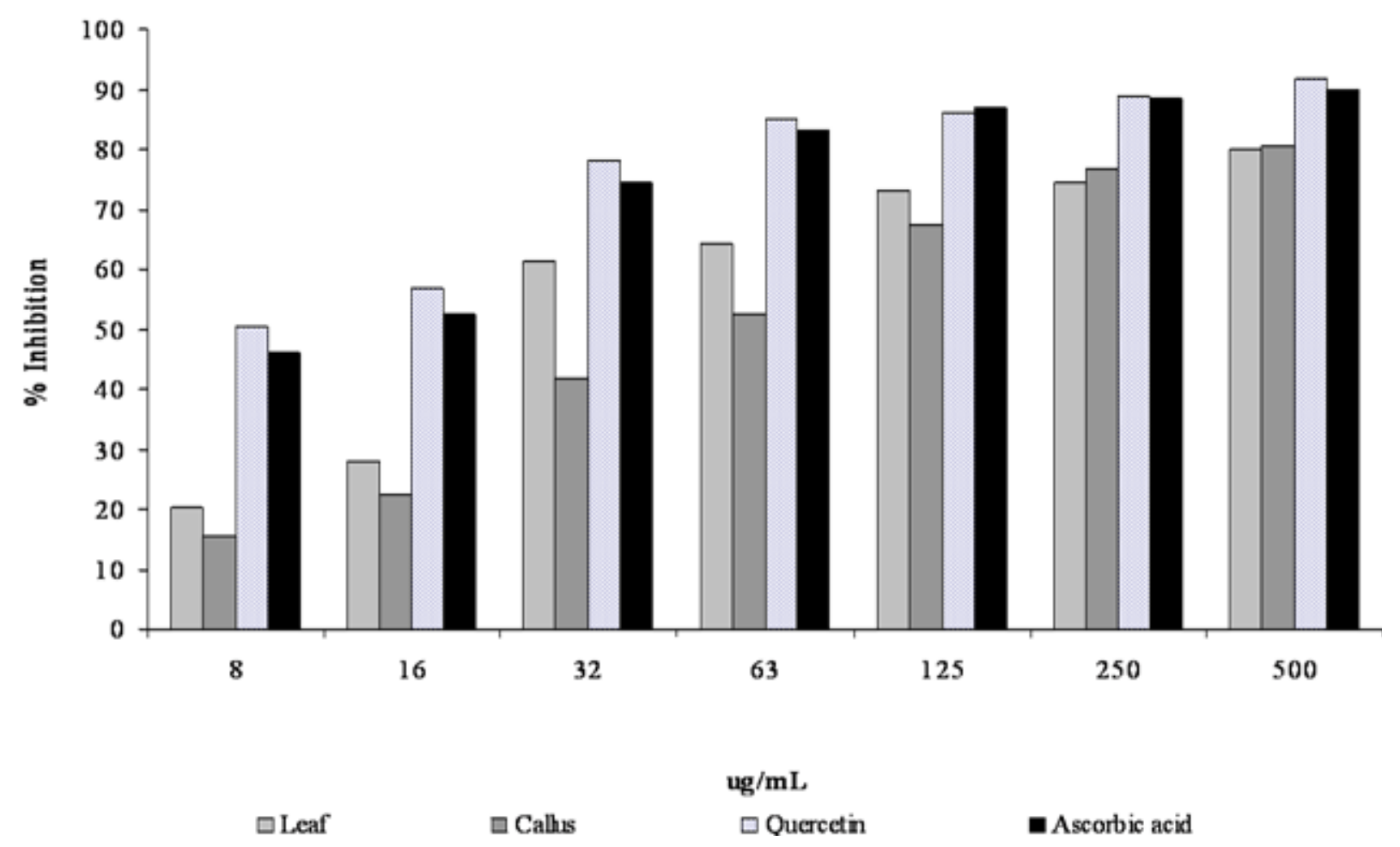

Figure 7. The antioxidant potential of leaf and callus methanolic extract using DPPH assay.

ted (Hairiah et al., 1993; Hartkamp et al., 2002; Hussain et al., 1997). An in vitro antioxidant study was also carried out by them. This study shows that $M$. pruriens possesses dose-dependent protection against superoxide generation, hydroxyl radical production and FeSO4induced lipid peroxidation. In vivo study showed significant inhibition in lipid peroxidation induced by alloxan and immobilized stress. In the present study, the antioxidant potential of leaf and callus methanolic extract using DPPH assay was carried out (Figure 7). All the extracts showed significant antioxidant activity at concentration of $500 \mu \mathrm{g} / \mathrm{mL}$ compared to the standard antioxidants ascorbic acid and quercetin. The methanolic extract of callus and leaf was prepared to carry out preliminary phytochemical analysis, TLC profile, and antibacterial activities. The preliminary phytochemical analysis of leaf and stem showed the presence of alkaloids, carbohydrates, glycosides, saponins, proteins, phenolics and phytosterols, whereas the callus extract did not respond to foam test, which confirms the absence of saponins in callus extract. Common spots with similar $R_{f}$ values in TLC of leaf, and callus extracts were identified. This confirms the presence of compounds in callus which is present in wild plant. Hence, isolation of bioactive compounds can be achieved through callus by cell-suspension culture without affecting the natural habitat of this important medicinal plant. According to the study of Karou et al. (2003), the methanolic extract of $M$. pruriens showed broad-spectrum antimicrobial activity concentration, no inhibition zone was observed in $P$. aeruginosa wells of leaf extracts, whereas activity was observed (Kokoska et al., 2002; Mary, 1992; Norman et al., 1985). Callus extract showed moderate activity against $P$. aeruginosa. An increase in the concentration of extracts can possibly give an inhibition zone. Hence, a further work on $P$. aeruginosa is required to find out the concentration. All other bacteria tested in the present study were almost similar to that obtained by Salau and Odeleye (2007). In conclusion, further trials are required for confirmation and isolation of bactericidal compounds from the in vitro callus.

\section{ACKNOWLEDGEMENTS}

Author is thankful to VIT University and Madras for providing laboratory facility.

\section{REFERENCES}

Aguiyi JC, Igweh AC, Egesie UG, Leoncini R (1999) Studies on possible protection against snake venom using Mucuna pruriens protein immunization. Fitoterapia. 70: 21-24.

Ahenkora K (1999) Composition and functional properties of raw and heat processed velvet bean (Mucuna pruriens (L.) DC. var. utilis) flours. J. Food Sci. Tech. 34: 131-135.

Ani A (2008) The Feeding Value of Processed Velvet bean (Mucuna pruriens) For pullet Chicks. J. Trop. Agr. Food Environ. Ext. 7( 2): $149-155$.

Azontonde A, Feller C, Ganry F, Remy JC (1998) The use of Mucuna for restoring the properties of a ferralitic soil in southern Benin. In: Tropical soils: some organic matter management trials. Agricultureet-Development 18: 55-62. 
Bell EA and Janes DH (1971). Medical and ecological consideration of L-dopa and 5HTP in seeds. Nature. 229:136-7.

Brain KR (1976) Accumulation of L-dopa in cultures from Mucuna pruriens. Plant Sci. Lett. 7: 157-161.

Chaudhri RD (1996). Herbal drug industry- a practical approach to industrial pharmacognosy. New Delhi: Eastern Publishers.

Cos P, Vlietinck AJ, Berghe DV, Maes L (2006) Anti-infective potential of natural products: How to develop a stronger in vitro "proof-ofconcept'. J Ethnopharmacology 106: 290-302.

Cowan MM (1999) Plant Products as Antimicrobial Agents. Clin. Microbiol. Rev. 12: 564-582.

Dako DYand Hill DC (1977) Chemical and biological evaluation of Mucuna pruriens (utilis) beans. Nutr. Rep. Int. 15: 239- 244.

Djeridane A, Yousfi M, Nadjemi B, Maamri S, Djireb F, Stocker P (2006) Phenolic extracts from various Algerian plants as strong inhibitors of porcine liver carboxylesterase. J. Enzym. Inhib. Med. Ch. 21: 719726.

Dongre AR, Opiteck G, Cosand, WL, Hefta SA (2001) Proteomics in the post-genome age. J. Pept. Sci. 60: 206-211.

Eilittä IM and Carsky RJ (2003). Efforts to improve the potential of mucuna as a food and feed crop: Background to the workshop. Tropica Subtropica Agroecosystems. 1: 47-55.

Guerranti R, Aguiyi J, Neri S, Leoncini R, Pagani R, Marinello E (2002) Proteins from Mucuna pruriens and enzymes from Echis carinatus venom: Characterization and cross reactions. J. Biol. Chem. 277: $17072-17078$.

Guerranti R, Aguiyi JC, Errico E, Pagani R, Marinello E (2001) Effects of Mucuna pruriens extract on activation of prothrombin by Echis carinatus veno. Ethanopharmacol. 75: 175-180.

Gurumoorthi P and Uma S (2011) Heat-stable and heat-labile antinutritional profile in Mucunapruriens var utilis: Effected by germination. J. Int. Food Res. 18(4): 1421-1426.

Hairiah K, Van noordwijk M, Setijano S (1993) Tolerance to acid soil conditions of the velvet beans (Mucuna pruriens var utilis and $M$. deeringiana). II. Above-ground growth and control of Imperata cylindrica. J. Plant Soil. 152: 175-185.

Hairiah K, Noordwijk, MV, Setijono S (1993) Tolerance to acid soil condition of the velvet beans Mucuna pruriens var.utilis and M.deeringiana. J Plant sci. 152: 175-185.

Hartkamp AD, Hoogenboom G, Gilbert R, Benson T, Tarawali sa, Gijsman A, Bowen W, White JW (2002) Adaptation of the CROPGRO growth model to velvet bean (Mucuna pruriens): II Cultivar evaluation and model testing. Field Crops Res. 78: 27-40.

Hussain G and Manyam B (1997) Mucuna pruriens proves more effective than L-DOPA in Parkinson's disease animal model. Phytother. Res. 11: 419-423.

Karou D, Dicko MH, Sanon S, Simpore J, Traore AS (2003) Antimalarial activity of Sida acuta Burm. f. (Malvaceae) and Pterocarpus erinaceus Poir. (Fabaceae). J. Ethnopharmacol. 89: 291-294.

Kokoska L, Polesny Z, Rada V, Nepovim A, Vanek T (2002) Screening of some Siberian medicinal plants for antimicrobial activity. J. Ethnopharmacol. 82: 51-53.

Manyam BVand Parikh KM (2002). Anti Parkinson's activity of Mucuna pruriens seed. Ann. NeuroSci. $11: 419-423$
Mary Josephine RKJ (1992) Studies on chemical composition and antinutritional factors in three germplasm seed materials of the tribal pulse, Mucuna pruriens (L.) DC. Food Chem. 43: 13-18.

Norman R, Farnsworth OA, Audrey S, Bingel D, Soejarto D, Zhengang G (1985) Medicinal plants in therapy. Bull World Health Organ. 63(6): 965-981.

Pant M and Joshi L (1970) Identification of pharmacologically active substance in the seeds of Mucuna pruriens DC. Ind. J. Pharmacol. 2: 24-29.

Rai M, Deshmukh P, Gade A, Ingle A, Kövics GJ, Irinyi L (2009) Phoma Saccardo: Distribution, secondary metabolite production and biotechnological applications. Crit. Rev. Microbiol. 35: 182-196.

Salau AO and Odeleye OM (2007). Antimicrobial activity of Mucuna pruriens on selected bacteria. African Journal of Biotechnology Vol. 6 (18), pp. 2091-2092, Scotter MJ (2011) Emerging and persistent issues with artificial food colours: natural colour additives as alternatives to synthetic colours in food and drink. Quality Assurance and Safety of Crops and Foods 3: 28-39.

Siddhuraju P, Becker K, Makkar HPS (2000) Studies on the nutritional composition and antinutritional factors of three different germplasm seed materials of an under-utilized tropical legume, Mucuna pruriens var. Utilis. J. Agric. Food Chem. 48: 6048-6060.

Sathyanarayana NS, Kameshwari S, Lilambika M, Harini S (2008). Optimization of DNA isolation and PCR-RAPD methods for molecular analysis of Urginea indica Knuth. Int. J. Integrative Biol. 2: 138-144

Sim S, Fung S, Tan N, Marinello E, Roberto G, Aguiyi JC (2006) Effect of pretreatment with Mucuna pruriens seed extract on the pharmacological effects of Naja naja sputatrix (Malayan cobra) venom in rats. Acta Pharmacologica Sinica.1: 326.

Singleton VL and Rossi JA (1965). Colorunetry of total phenolics with phosphomolybdic-phosphotungstic acid reagents. Am. J. Enol. Viticult. 16:144-58.

Szabo NJ and Tebbett IR (2000) The chemistry and toxicity of Mucuna species. In: Flores M, Eilittä M, Carsky R, Myhrman R, Carew L, Rojas J (Eds.). Food and Feed From Mucuna: Current Uses and the Way Forward. Proceedings of a workshop held inTegucigalpa, Honduras: 26-29.

Tripathi YB and Upadhyay AK (2002) Effect of the alcohol extract of the seeds of Mucuna pruriens on free radicals and oxidative stress in albino rats. Phytother. Res.. 16: 534-538.

Vaidya R, Sheth A, Aloorkar S, Rege N, Bagadia V, Devi P, Shah L (1978) The inhibitory effect of the cowhage plant-Mucuna pruriensand Ldopa on chlorpromazine- induced hyperprolactinaemia in man. Neurol. Ind.. 26(4): 177-178.

Yamini B, Tripathi, Anil KU (2002) Effect ofAlcohol Extract of the Seeds of Mucuna pruriens on Free Radicals and Oxidative Stress in Albino Rats. Phytother. Res. 16: 534-538. 